\title{
Remote sensing study of soil hazards for Odendaalsrus in the Free State Province
}

\author{
Patrick Cole ${ }^{1}$, Janine Cole ${ }^{2}$, Souleymane Diop ${ }^{3}$, Marinda Havenga ${ }^{4}$ \\ ${ }^{1}$ Council for Geoscience, Pretoria, South Africa, pcole@geoscience.org.za \\ ${ }^{2}$ Council for Geoscience, Pretoria, South Africa, jcole@geoscience.org.za \\ ${ }^{3}$ Council for Geoscience, Pretoria, South Africa, sdiop@geoscience.org.za \\ ${ }^{4}$ Council for Geoscience, Pretoria, South Africa, marindah@geoscience.org.za
}

DOI: $\underline{\text { http://dx.doi.org/10.4314/sajg.v4i2.7 }}$

\begin{abstract}
Expansive soils are some of the most widely distributed and costly of geological hazards. This study examined ASTER satellite data, combined with standard remote sensing techniques, namely band ratios, in identifying these soils. Ratios designed to detect various clay minerals were calculated and possible expansive soils were detected, especially in the pans. It was also possible to delineate the mudrock that may act as a source for expansive soils. Moisture content clearly affected the ratios and it shows that remote sensing can detect where wetness leads to the development of problem soils. The fact that the area has relatively dry climatic conditions may explain why large areas of the mudrock have not yet weathered to clays. Because the ratios are not unique, results can be ambiguous, so care must be taken in the interpretation phase.
\end{abstract}

\section{Introduction}

Expansive and collapsible soils are some of the most widely distributed and costly of geological hazards. These soils are characterized by changes in volume and settlement, commonly triggered by water. The use of remote sensing data to identify these problem soils is an attractive option, being able to cover extensive areas for the identification of such hazards in a cost-effective way.

Expansive soils comprise clay-rich materials, the most common of which are kaolinite, illite, smectite and montmorillonite (Yitagesu et al., 2011). The formation of different clay minerals depends on factors such as parent rock, climate, transportation, burial and diagenesis (Galán, 2006). Their propensity for swelling depends on their lattice structure. Kaolinite for example, has a lattice structure that is not prone to swelling (Williams et al., 1985) whereas illite, smectite and montmorillonite are conducive to expansion. 
Remote sensing data have historically been adept at identifying clays (e.g. clay ratio). The concept of using ASTER data for shrink-swell clays is not new (Bourguignon et al., 2007). This study seeks to examine the effectiveness of ASTER satellite data, combined with standard remote sensing techniques, in identifying these soils.

\section{Study area and data}

The area chosen for study is the Odendaalsrus locality, which is a well known historical site for expansive soils.

The study area (Odendaalsrus 2726DC) falls within the Free State Province of South Africa (Figure 1). Aeolian sand of Quaternary age covers most of the area, with some mudrocks of the Karoo Supergroup outcropping in the south. Allanridge lavas, shales and conglomerates of the Ventersdorp Supergroup are the oldest rocks in the area.

The study area falls in the semi-arid to sub-tropical climatic zone with mean annual rainfalls between 250 and $500 \mathrm{~mm} /$ year. The rainfall occurs primarily in the summer months due to thundershower activity.

The climate is essentially a continental one with warm, wet summers and relatively cold winters. The mean maximum annual temperature for the majority of the region ranges between $29^{\circ} \mathrm{C}-35^{\circ} \mathrm{C}$, with the mean minimum annual temperature ranging between $2^{\circ} \mathrm{C}-2.6^{\circ} \mathrm{C}$.

The area is classified as having a climatic N-value between 2 and 5 . Weinert (1980) was able to relate the $\mathrm{N}$-value to the weathering characteristics of materials ( $\mathrm{N}<5$ decomposition, i.e. chemical weathering dominates; $\mathrm{N}>5$ disintegration, i.e. physical weathering dominates), and the general characteristics of soils formed in a particular area.

Soils developing due to in situ chemical weathering from shales and mudrock of the Ecca and Beaufort Groups have been identified as potential expansive soils (Williams et al., 1985). In the study area the Volksrust and Normandien Formations represent these two groups respectively. Dark-grey mudstone, siltstone and fine-grained sandstone of the Volksrust Formation are visible throughout the area, most predominantly in the south (Figure 1). Beuhmann and Beuhmann (1990) analysed mudrock and siltstone from this formation extracted from borehole core near Bothaville (50 km north of Odendaalsrus). They observed that 2:1 layer silicates dominated the clay minerals and that illite/smectite interstratifications randomly occurred. Discrete smectite was found in the 
upper weathered part of the Volksrust Formation. Kaolinite was also widely present but they could find no direct correlation between the presence of kaolinite and lithological composition.
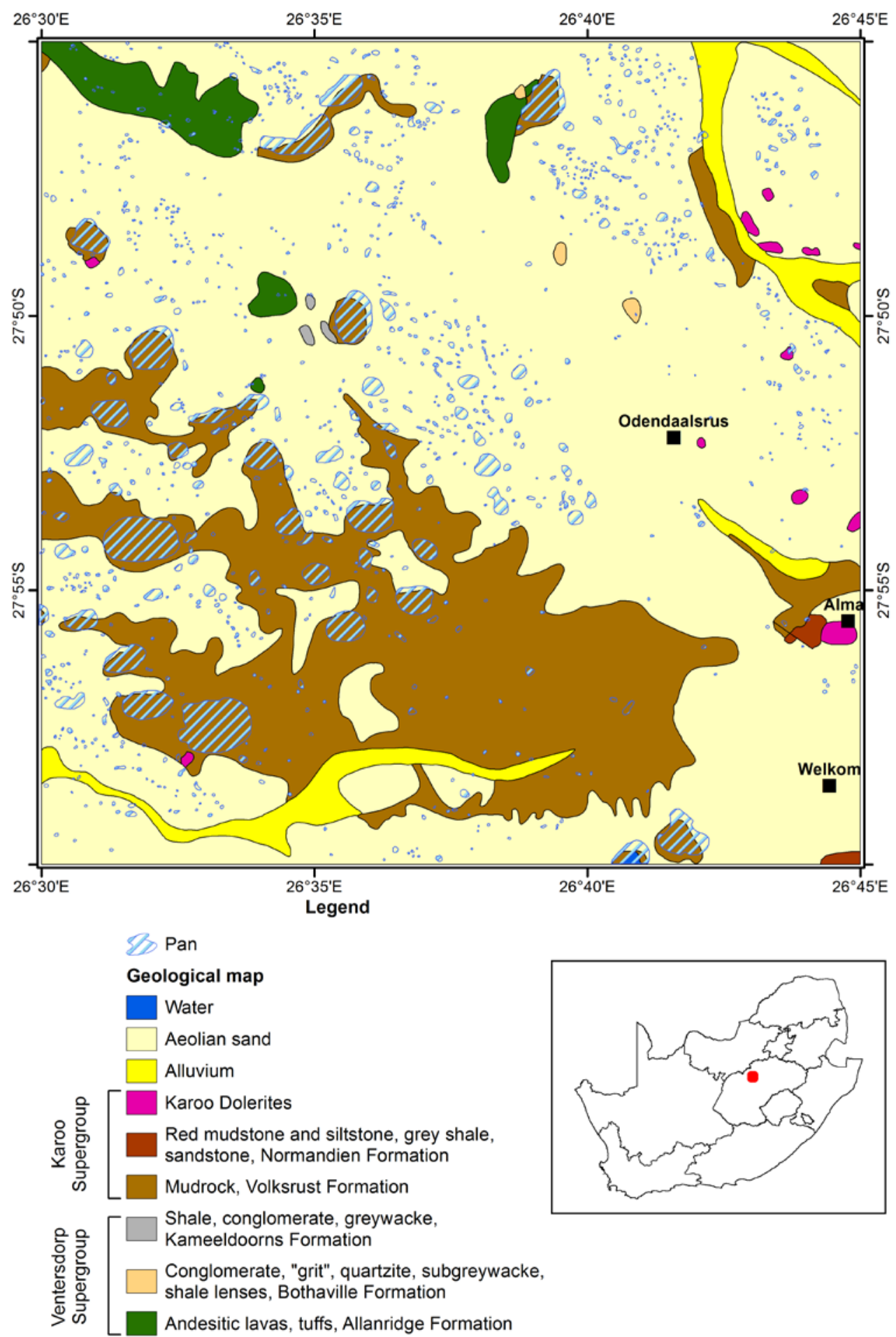

Figure 1. Geological map for the Odendaalsrus sheet (from Council for Geoscience, 2000 and Schutte , 1993). The inset shows the locality within South Africa. 
ASTER (Advanced Spaceborne Thermal Emission and Reflection Radiometer) data were selected for this study for two main reasons, namely the number of bands and the low cost per scene. The ASTER instrument collects data in 14 bands, three of which are in the visible and nearinfrared (VNIR) wavelengths, six in the shortwave infrared (SWIR) wavelengths and five in the thermal (TIR) wavelengths. The six SWIR bands are ideally suited to studying the spectral signatures of minerals composing different rock types.

Two scenes collected at different times were obtained (Figure 2). One scene (14 January 2002) was collected during the rainfall season in late summer, and it can be assumed that the area was wetter than in late winter/early spring 2007 when the second scene was collected. The seasonal differences between the scenes will illustrate variations in effects of moisture on different materials.

ASTER Level 3A data were chosen since the data are already orthorectified. Standard preprocessing techniques including layer stacking, radiometric calibration and atmospheric correction (using the log residual algorithm) were applied to the data before analysis of the data could be done.

Different land use types cover the area (Figure 2). Agricultural workings are visible throughout the map area, but are most prevalent in the north and southwest. Towns are located in the southeastern corner and just east of the middle of the map. The area has a rich gold mining history, and slimes dams related to the mining activities are visible, mostly in the southeast but there is also a dam in the north. 
(a)

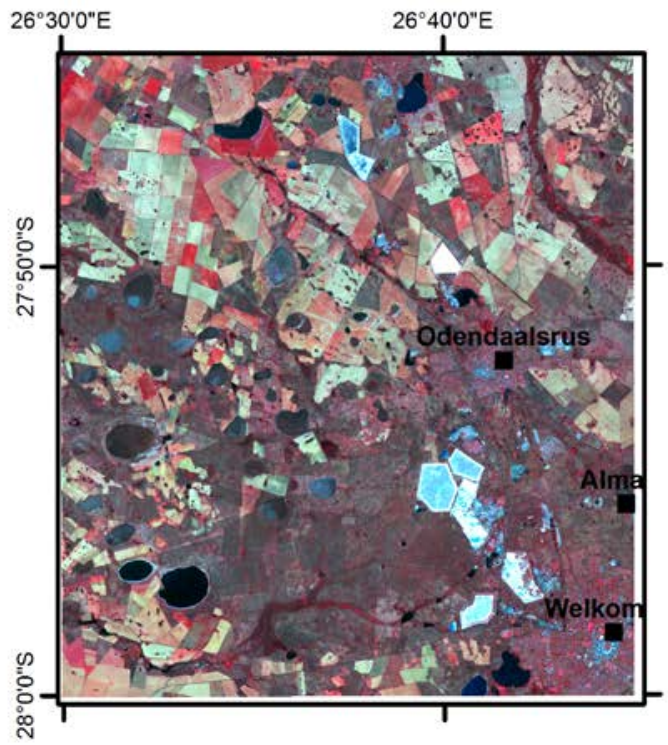

(b)

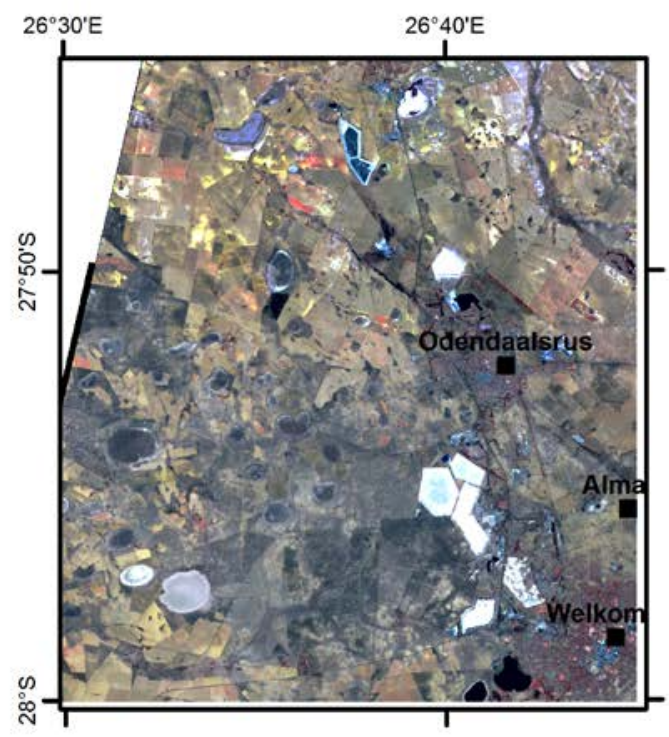

Figure 2. Ternary image of the ASTER data for 2726DC collected on (a) 14 January 2002 and (b) 9 September 2007. Bands 3, 2 and 1 were assigned to the red, green and blue bands respectively

\section{Analysis and discussion}

The spectral signatures for the most common clay minerals show subtle differences in the SWIR wavelength range, but the limited spectral coverage of ASTER data does not sample all of these differences (Figure 3). This is one of the limitations of multispectral data compared to hyperspectral data, but the high cost of acquiring the latter prohibits its widespread use in reconnaissance studies. All the clays have a strong absorption feature in band 6. For kaolinite an additional absorption feature is located in band 5, making it possible to distinguish kaolinite from the other clay minerals. There are no clear distinguishing features in the SWIR bands between illite, smectite and montmorillonite. 


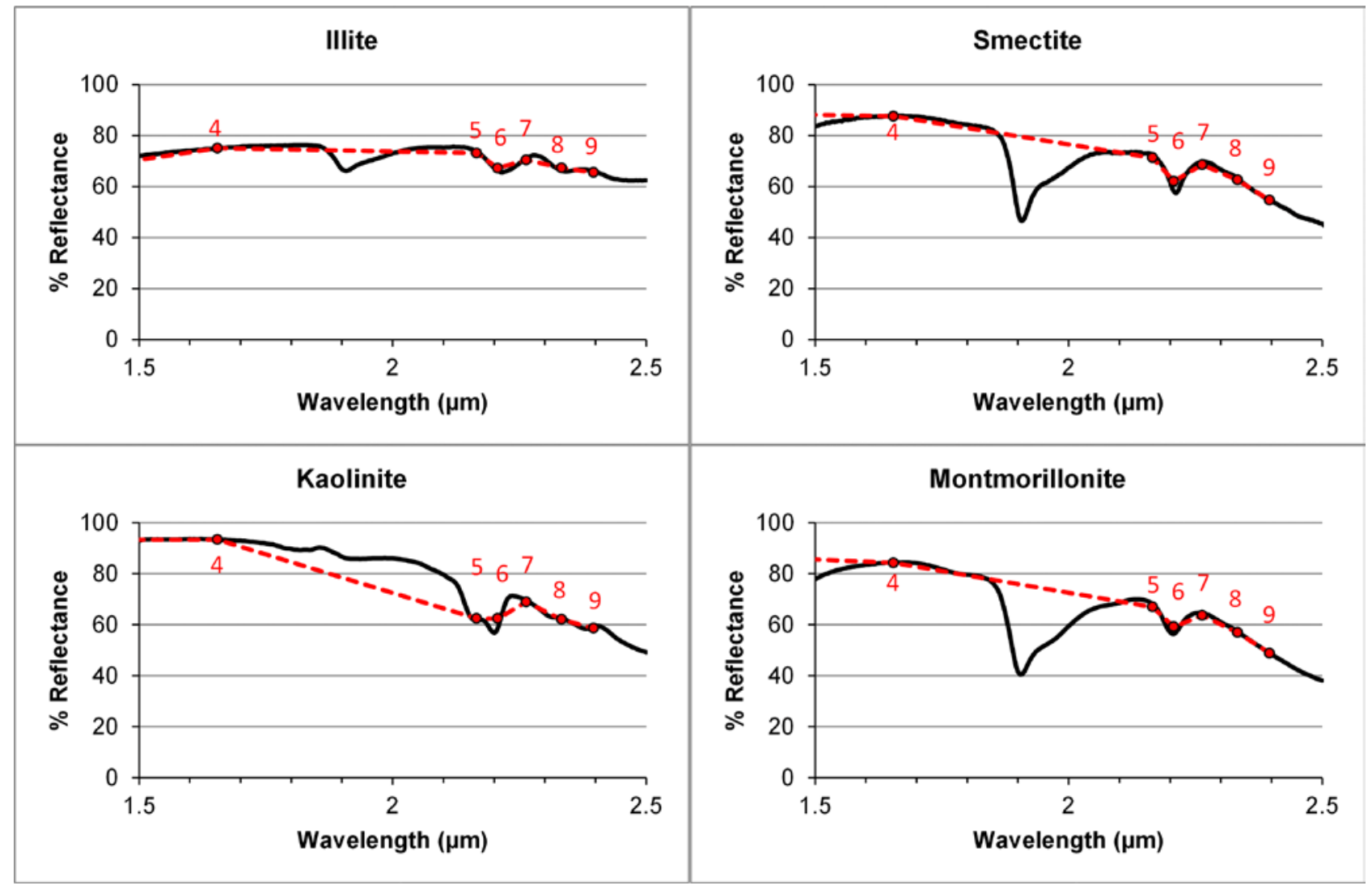

Figure 3. Example spectra in the SWIR range for the most common clay minerals (Baldridge, 2009). The black line shows the full spectrum, red dashed line is the spectrum down sampled to ASTER bands (numbers indicated in red)

Band ratios are widely used to discriminate between spectra collected for different minerals, vegetation types etc. An absorption feature can also be emphasised by calculating relative absorption band depths. Data from absorption band shoulders are added and divided by data in the absorption band minimum (Crowley et al., 1989). Various band ratios and band depth ratios have been published for ASTER data (Gozzard, 2006). The most appropriate ratios for identifying clay minerals from Gozzard (2006) are (5+7)/6 (sericite/muscovite/illite/smectite), (4+6)/5 (alunite, kaolinite/pyrophylite) and 7/5 (kaolinite). By comparing the spectrum of a particular mineral to any of these ratios one can easily see whether a ratio is applicable to the mineral.

Prior to calculating these ratios, the vegetation was masked by eliminating areas where the Normalised Difference Vegetation Index (NDVI) $>0.2$. The agricultural fields in the north yielded high clay ratios but are not of interest in this study. Spectra were collected from the ASTER data sets to determine whether there is a difference between the spectra of the agricultural fields and the mudrock (Figure 4). The 'Spectral Profile' tool in Exelis ENVI was used to extract spectra from the 
data set and these were then exported to ASCII files. The extracted values at each ASTER band were then simply averaged. The biggest distinguishing feature is the relation between bands one and two. For the agricultural fields band two is more reflective than band one in both the wet and dry seasons, whereas this is not the case for the pans and mapped mudrock. This relation was used to mask out the agricultural fields.
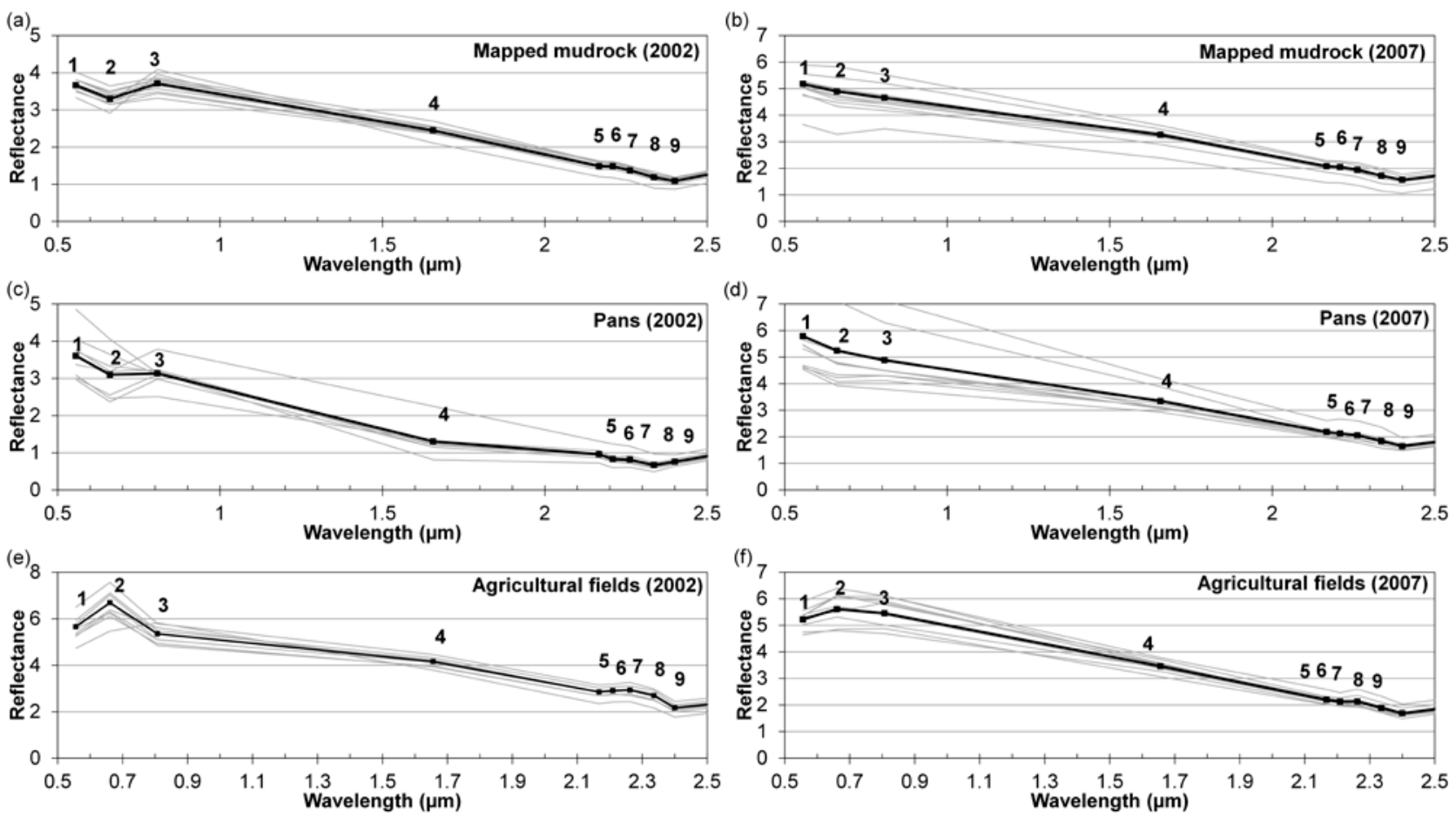

Figure 4. Spectra collected from the ASTER data sets. The grey lines are the collected spectra and the black lines are the average calculated for each material type. Band numbers are indicated.

For the (4+6)/5 (Figure 5a and b) and (5+7)/6 ratios (Figure 5c and d) values above 2.0 show the possible presence of the targeted materials, and for 7/5 (Figure $5 e$ and $\mathrm{f}$ ) values above 1.0 are of interest. The (4+6)/5 ratio (Figure $5 \mathrm{a}$ and b) are above 2.0 in the south where mudrock have been mapped. Low values correlate with the water-filled pans while for the summer scene drier pans have values just above two but still lower than the mudrock areas. In the dry season many of the pans are indistinguishable from the mudrock. The ratio for the mudrock is generally lower in the dry season but still well above two.

The (5+7)/6 ratio is well designed to delineate illite/smectite/montmorillonite since it will highlight the absorption feature in band 6 (Figure 3a, b, d). In the wet season (Figure 5c) many of 
the pans are clearly delineated by this ratio. The mudrock itself has values below 2.0 indicating no direct correlation with these spectra. The reason for this is clearly visible in the spectra that were collected from the scene (Figure 4a, d). The distinctive absorption feature in band 6 is present in the pans but is absent in the mapped mudrock. Many of the pans however developed on the mudrock (Figure 1) and the presence of smectite/illite can point to the possible development of these clays in the mudrock if sufficient water is present. The importance of water is further illustrated by the lower ratios in the pans for the dry scene (Figure 5d). Many of the pans are barely visible and only the wetter pan in the southwest can be delineated. Values above 2.0 are also present in the built-up areas and in the river beds, especially in the northeast.

Figure 6 shows that a large majority of the slope are relatively flat (less than $5^{\circ}$ ) and can rightly be considered as waterlogged. Therefore drainage is a possible concern as evidence by the scattering of pans across the study area.

According to Weinert (1980), the above conditions are conducive to weathering being deep in accordance with the climatic environment. Montmorillonite is the principal clay mineral formed on decomposing basic crystalline rocks; it is the final decomposition product where $\mathrm{N}$ is between 2 and 5. This would explain the development of expansive clays in the pans which formed where water collected on the mudrock.

The kaolinite ratio (7/5) seeks to separate kaolinite from other clay minerals by the absorption feature coinciding with band 5 (Figure 3c). For both the wet and dry seasons (Figure 5e, f) a kaolinite signature is only visible in some of the mine dumps. None of the pans show up on these ratios. This ratio clearly differs from the (4+6)/5 ratio which is described by Gozzard (2006) as the 'alunite, kaolinite/pyrophylite' ratio. We can therefore deduce that the $(4+6) / 5$ ratio does not delineate kaolinite but another mineral that is associated with mudrock.

The three ratios were combined into ternary images to produce a ‘clay distribution' map (Figure 7). Green areas indicate the presence of smectite/illite type clays, red correlate with mudrock and blue is associated with kaolinite. On this image green, red and yellow (a combination of red and green) can be considered as possible areas where expansive soils can occur. 

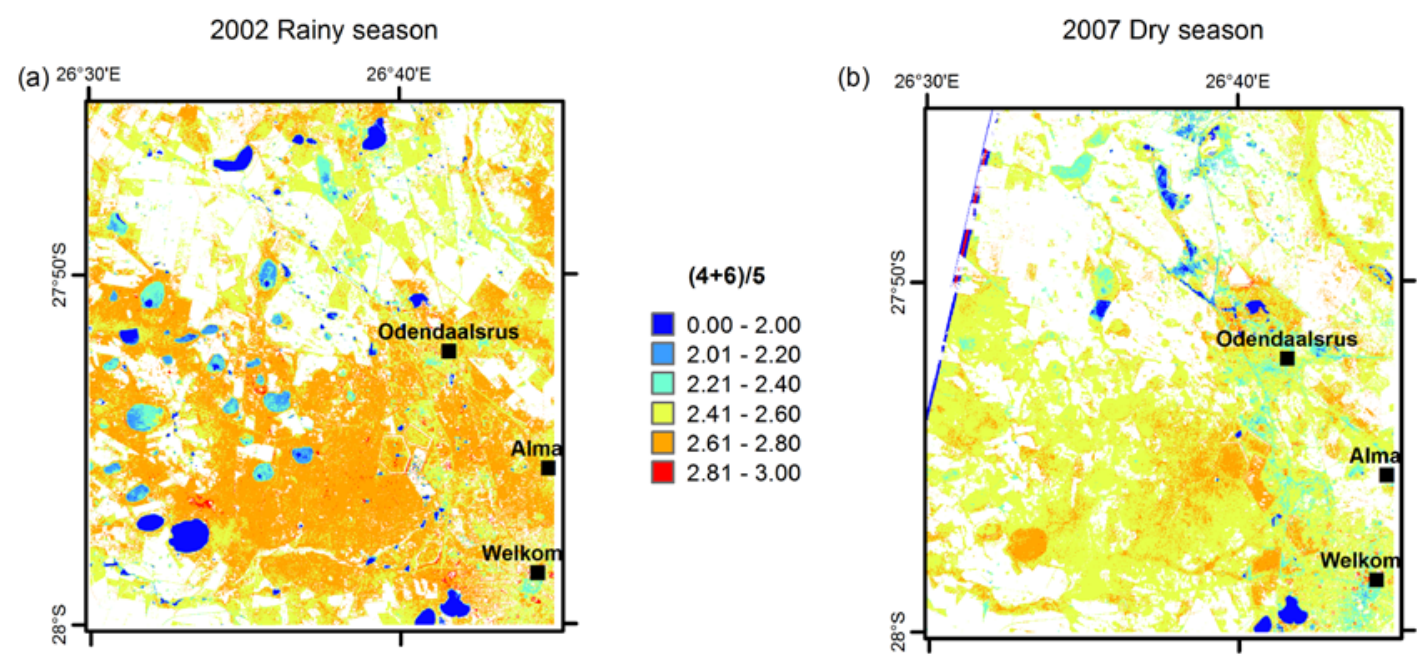

(c)
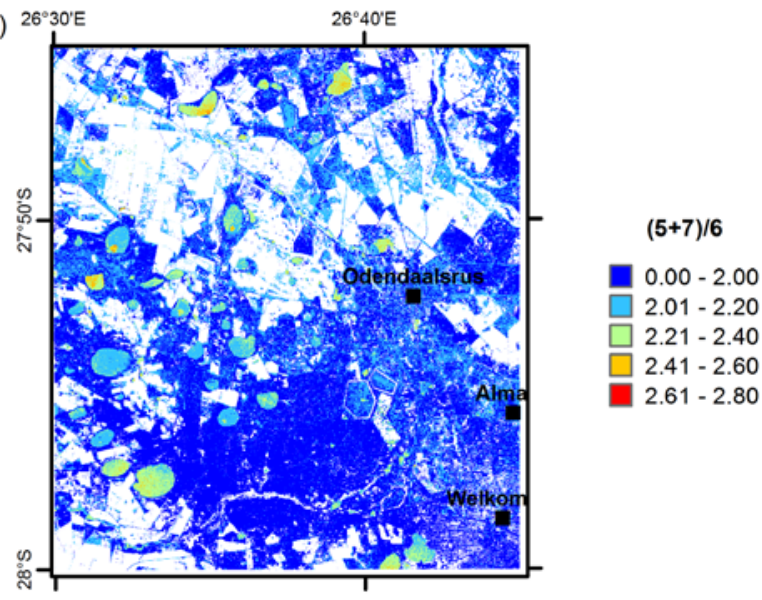

(d)
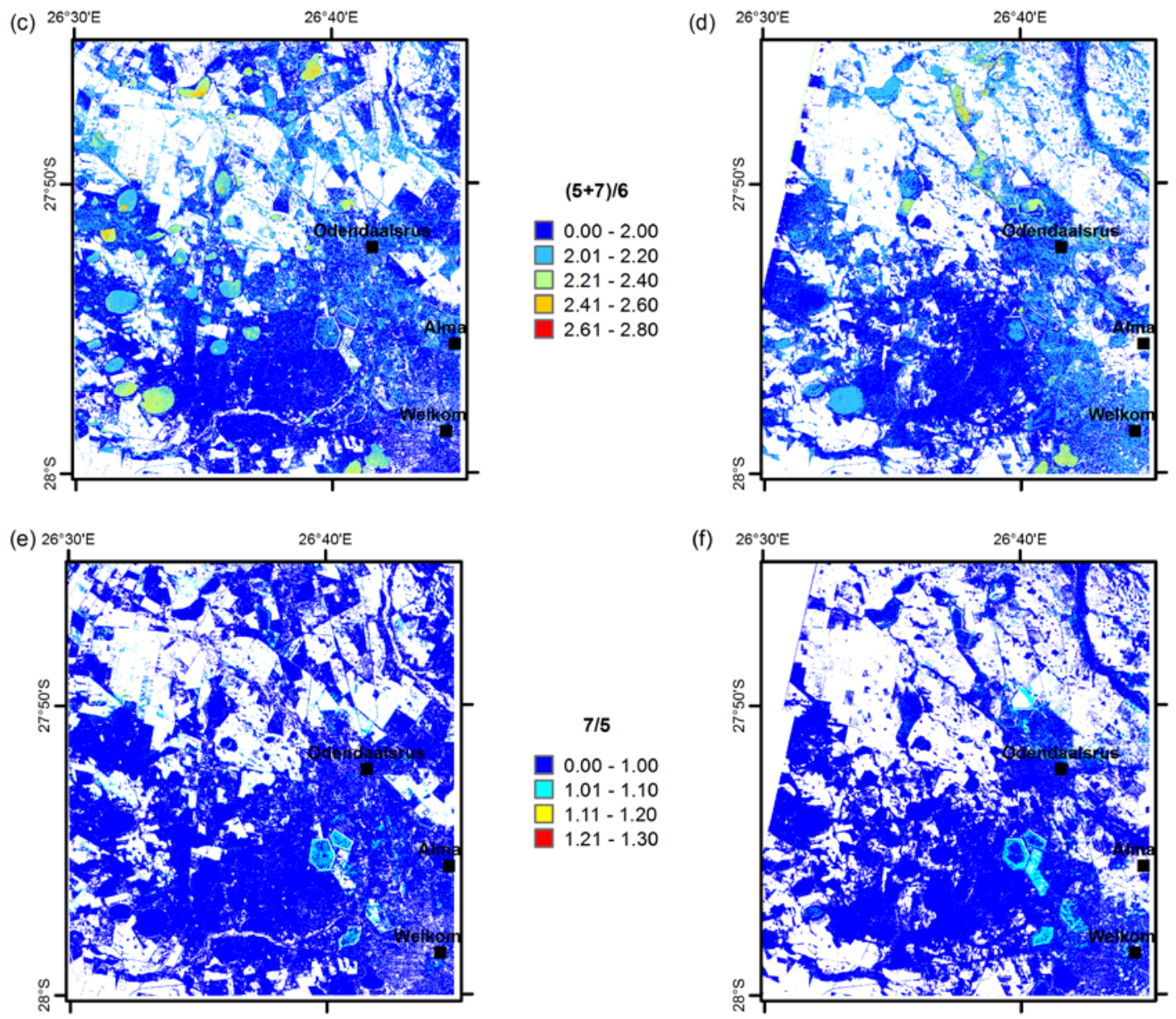

Figure 5. Band ratios calculated to emphasise (a) and (b) alunite, kaolinite and pyrophyllite; (c) and (d) sericite, muscovite, illite and smectite; (e) and (f) kaolinite. White areas are masked vegetation and agricultural fields. 
South African Journal of Geomatics, Vol. 4, No. 2, June 2015

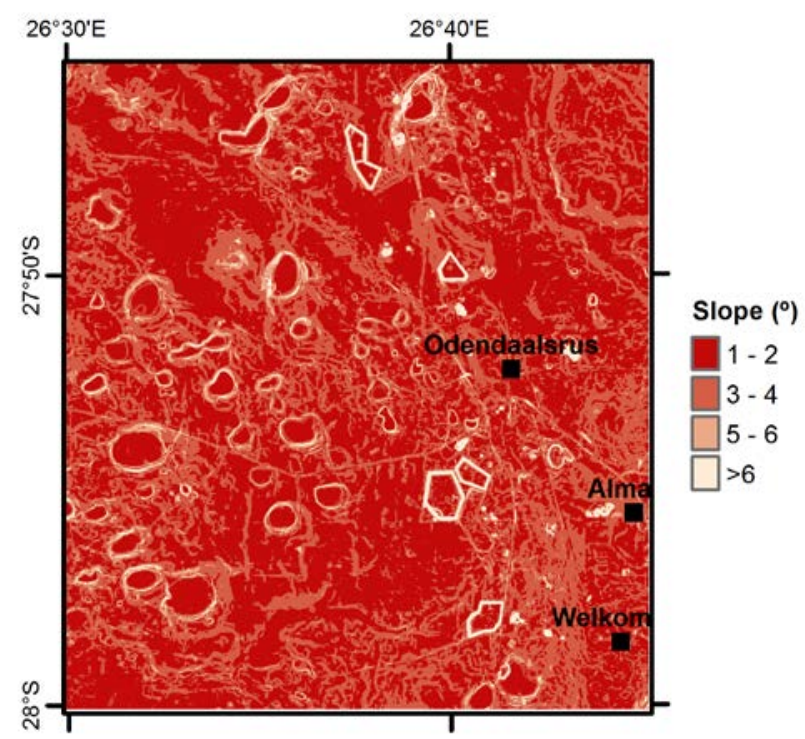

Figure 6. Slope class map

2002 Rainy season

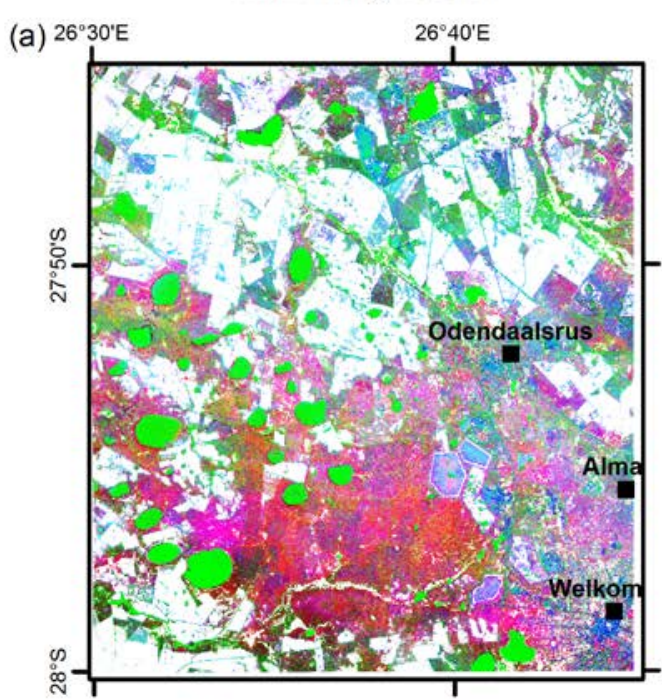

2007 Dry season

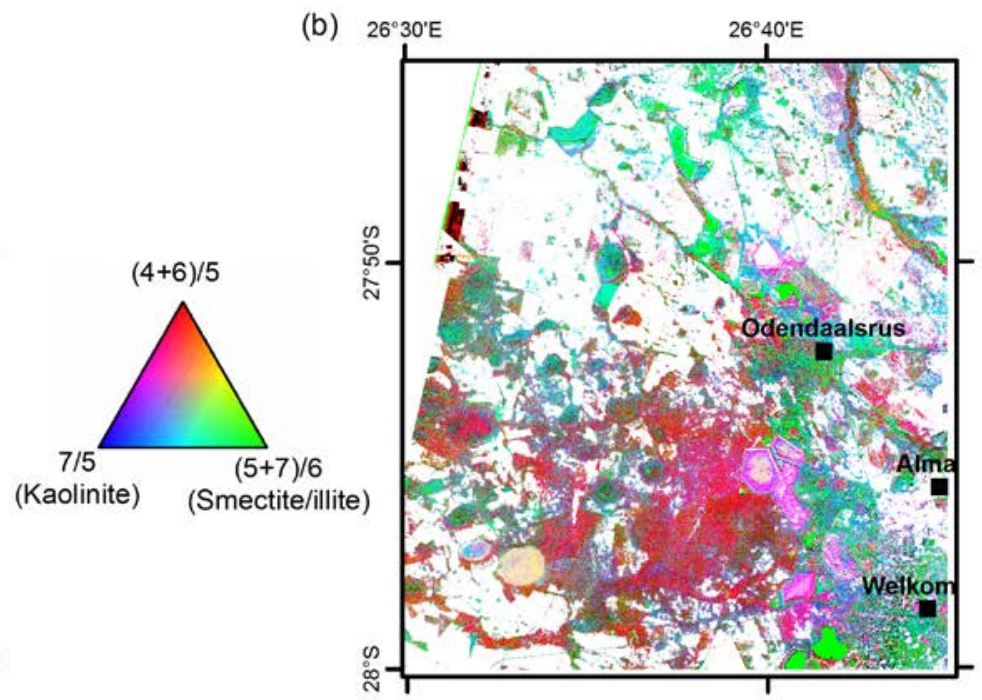

Figure 7. Ternary images combining the ratios into red, green and blue bands. 


\section{Conclusions}

The initial ratio calculations appear to show a lack of expansive soils in the area where mudrock has been mapped. However, further studies of additional band ratios, observed spectra as well as incorporating geotechnical constraints (eg. slope) revealed signatures associated with the problem soils around Odendaalsrus. The seasonal variation in clay signatures also confirmed this. The area where mudrock is present in the south can be considered a high risk for the development of expansive soils under the right conditions.

The process of using or designing band ratios based on mineral spectra can be effective at identifying hazardous soils. However, care must be taken to view the results within the context of the local geotechnical information and climatic conditions. Snap decisions (such as deciding that there are no hazardous soils based on low clay ratios) should absolutely be avoided.

Remote sensing data can play a valuable role in hazard detection. The ability to cover large areas in a short period of time is useful in reducing the amount of time in determining hazards. Although there are limitations in using multispectral data, the fact that the data sets are easy and economic to obtain makes them suitable to a project of this nature. These data types therefore have a role to play in determining hazards.

\section{References}

Baldridge. A.M., Hook, S.J., Grove, C.I., Rivera, G. 2009. The ASTER spectral library version 2.0. Remote Sensing of Environment, 113, 711-715.

Beuhmann, C., Beuhmann, D. 1990. Clay minerals as palaeoenvironment indicators exemplified on a Karoo Sequence from the Bothaville area, South Africa. South African Journal of Geology, 93, 505-513.

Bourguignon, A., Delpont, G., Chevrel, S., Chabrillat, S. 2007. Detection and mapping of shrink-swell clays in SW France, using ASTER imagery. In: Mapping Hazardous Terrain Using Remote Sensing, R. M. Teeuw (Ed.), Geological Society London, Special Publication, 283, pp. 117-124

Council for Geoscience, South Africa, 2000. 2726 Kroonstad. Geological Map Series. Compiled by Schutte, I.C., from mapping by Schutte, I.C., Minnaar, C.L.J., Allcock, R.J., Zawada, P.K. \& Stepto, D

Crowley, J.K., Brickey, D.W., Rowan, L.C. 1989. Airborne imaging spectrometer data of the Ruby Mountains, Montana: Mineral discrimination using relative absorption band-depth images. Remote Sensing of Environment, 29, 121-134. 
South African Journal of Geomatics, Vol. 4, No. 2, June 2015

Galán, E. 2006. The genesis of clay minerals, in F Bergaya, B KG Theng and G Lagaly (eds.), Handbook of Clay Science, Development in Clay Science Volume 1, Elsevier, Amsterdam.

Gozzard, J.R. 2006. Image processing of ASTER multispectral data. Western Australia Geological Survey, Report 2006/9, 51 pp.

Schutte, I.C. 1993. Die geologie van die gebied Kroonstad. Explanation of sheet 2726. Council for Geoscience, Pretoria, 84 pp.

Weinert, H.H. 1980. Natural road construction materials of Southern Africa. Academica, Pretoria, 298 pp.

Williams, A.A.B., Pidgeon, J.T., Day, P.W. 1985. Problem soils in South Africa - state of the art: Expansive soils. The Civil Engineer in South Africa, July, 367-377.

Yitagesu, F.A., Van der Meer, F., Van der Werff, H., Hecker, C. 2011. Spectral characteristics of clay minerals in 2.5 - $14 \mu \mathrm{m}$ wavelength region. Applied Clay Science, 53, 581-591. 